\title{
The influence of hyperbaric oxygen therapy (HBOT) to intercausal relationship between blood vessels, osteoblast, and new bone formation during maxillary suture expansion
}

\author{
Noengki Prameswari ${ }^{1}$, Iwa Rahmat Sunaryo ${ }^{2 *}$, Dian Widya Damayanti ${ }^{3}$, Agni Febrina $^{3}$
}

\author{
${ }^{1}$ Department of Orthodontics, Faculty of Dentistry Hang Tuah University, Indonesia \\ 2Department of Orthodontics, Faculty of Dentistry Universitas Padjadjaran, Indonesia \\ ${ }^{3}$ Department of Oral Biology, Faculty of Dentistry Hang Tuah University, Indonesia
}

\begin{abstract}
Introduction: Expansion appliance that can imply tooth movement and opening maxilla suture might affect the blood vessels, bone cells, and formation of the new bone. HBOT accelerated the rate of osteoblast differentiation leading to an increase in bone formation during osteonecrosis. Research about HBOT during maxillary suture expansion has never been investigated. The purpose of this research was to correlate the blood vessels number, osteoblast by administered 2.4 ATA HBOT from day 8-14 to imply new bone formation during maxillary suture expansion. Methods: Eighteen male guinea pigs with randomised post-test only control group design divided into 3 groups. Negative control group K(-), positive control with expansion appliance $\mathrm{K}(+)$, expansion appliance and HBOT $(\mathrm{P})$. After 14 days guinea pigs were decapitated. Histological slide of the blood vessels number, osteoblast, and new bone formation were examined under a light microscope then were analysed by regression test. Results: Descriptive test showed increasing blood vessels number, osteoblast, and new bone formation on the administration of HBOT during maxillary suture expansion. Regression test showed that there was a strong correlation between the blood vessels number and osteoblast to the new bone formation with $\mathrm{R}=6.95$ during maxillary suture expansion. Conclusion: 2.4 ATA HBOT influences the intercausal relationship between increasing blood vessels number, increasing osteoblast, and new bone formation during maxillary suture expansion.
\end{abstract}

Keywords: HBOT, blood vessels, osteoblast, new bone formation, maxillary suture expansion.

p-ISSN: 1979-0201; e-ISSN: 2549-6212; Available from: http://jurnal.unpad.ac.id/pjd/article/view/19684

DOI: 10.24198/pjd.vol32no1.19684

Submission: 17 Dec 18; Accepted: Mar 03, 2020; Published online: Mar 31, 2020

"Corresponding author: Iwa Rahmat Sunaryo, Department of Orthodontics, Faculty of Dentistry Universitas Padjadjaran, Indonesia. Jalan Sekeloa Selatan I, Bandung, West Java, Indonesia, 40132. Phone: +628122313560; Email: iwa.sunaryo@ fkg.unpad.ac.id 


\section{INTRODUCTION}

Malocclusion is one of the most common morphogenic dentofacial abnormalities which remains an increasing problem thus requires many researches in the dentistry field to find its solution. ${ }^{1}$ Expansion appliance is one of orthodontic treatment can be used to correct malocclusion, maxillary transverse deficiency. ${ }^{2}$

Maxillary transverse discrepancy usually requires expansion of the palate by a combination of orthopedic and orthodontic tooth movements. Expansion appliance made the midpalatal suture that located between the maxillary bones in the palate and contains secondary cartilage is highly responsive. ${ }^{2}$ There are many kinds of maxillary expansion appliances and various recommended expansion rates, which can result in rapid maxillary expansion (RME) or slow maxillary expansion (SME). ${ }^{3}$

Midpalatal suture expansion, or rapid palatal expansion, has been used clinically with orthodontist for more than 40 years to correct maxillary width deficiencies. ${ }^{2}$ Maxillary expansion is a procedure to correct the posterior crossbite and transverse maxillary deficiency, and early treatment has been performed to correct the transversal discrepancy avoiding future extraction. ${ }^{3}$

Previous research showed dimensional changes in the midpalatal suture along with radiographic investigations, morphologic and histologic study that mechanical separation is multiple step healing process characterized by new bone and connective tissue formation, followed by remodelling. ${ }^{4}$ The roles of vessels have been well documented in various bone modeling situations. ${ }^{5}$ The underlying mechanisms that drive bone formation during this process are largely unknown, but it has been reported that tensional force applied to the midpalatal suture of rats induces the replacement of cartilaginous tissues by bone. ${ }^{2}$ It has been suggested that mesenchymal cells located on the inner side of the cartilaginous tissue proliferate and differentiate into osteoblasts when the suture is expanded. ${ }^{2}$ Generally, bone modeling is characterized by a tightly regulated positive coupling between osteogenesis and angiogenesis. ${ }^{5}$

Hyperbaric Oxygen Therapy (HBOT) is a method of medical treatment by inhaling pure
$100 \%$ oxygen continuously by the body with the air pressure that is greater than normal atmospheric pressure over specific time. ${ }^{6}$ HBOT has been proven to have beneficial effect in wounded area if $100 \%$ Oxygen breathed in HBOT chamber with pressure more than 1 ATA. ${ }^{7,8}$

This condition will spark the increase in fibroblast and angiogenesis that causes neovascularization of wounded area, collagen synthesis, also the increase and repair of microvascular blood flow. ${ }^{6}$ Oxygen is important in lysine and proline hydroxylation during the collagen synthesis process and also for the collagen bonding and maturation. ${ }^{9}$ Daily exposure to HBOT also known to accelerate the rate of osteoblast differentiation as determined by increased alkaline phosphatase activity and expression of type I collagen and Runx-2 mRNA during the early stages of culture. ${ }^{10}$ HBOT in maxillary suture expansion has not been investigated yet.

Research about HBOT in alveolar bone remodeling process during suture expansion has never been investigated before. Other research showed that the use of HBOT in 2,4 ATA in pressure area for 7 days is relatively better than 5 days in increasing tissue vascularization thus stimulates remodeling process. ${ }^{11}$ While the use of HBOT in 7 days and 10 days after inserting the orthodontic brackets showed that the use of HBOT 2,4 ATA in 10 days did not reflect significant increase as compared to the use of HBOT in 7 days. ${ }^{11}$

This research aims to correlate of blood vessels number, osteoblast by giving HBOT 2,4 ATA given from day 8-14 to imply new bone formation during maxillary suture expansion.

\section{METHODS}

\section{Animal preparation}

This research is a true experimental research with randomized post-test only control group design. Ethical permission was obtained from Ethics and scientific committee of experimental animal use at Faculty of dentistry Hang Tuah University 079/ KEPK/ III/2018.

This Research was conducted at Biochemistry laboratory Medical Faculty and Oral Biology Laboratory Hang Tuah University. Equipment used in this research are the Guinea pigs cage, Guinea pigs weighing scale, Waring Commercial Model 
HGBTWT, rubber separators, caliper, separating plier, maxillary expansion, pinset, cotton pellet, surgical scissors, small-sized coil, animal chamber for HBOT. Eighteens male guinea pigs from animal laboratory medical faculty Hang Tuah university with the criteria of: male, age of 3-4 months with bodyweight around 300-400 grams divided into 3 groups. Negative control group K(-), positive control with expansion appliance $\mathrm{K}(+)$, hyperbaric oxygen therapy $(\mathrm{P})$.

\section{Maxillary suture expansion preparation}

This research was started by acclimating the experimental animals for 7 days. After guinea pigs being acclimated, we divided them into three group: negative control group $\mathrm{K}(-), \mathrm{K}(+)$ and $\mathrm{P}$ group were given rubber separator in left incisive with tensile strength $0,29 \mathrm{gr} / \mathrm{cm} 2$ until the second day and the next day rubber separators were replaced with tensile strength $0,48 \mathrm{gr} / \mathrm{cm} 2$ until the third day to get diastema. From the $3^{\text {rd }}$ day until the $4^{\text {th }}$ day using diastema, helical spring was applied to expand maxillary. Rubber separators that is used from American Orthodontic. Helical spring selected in this research is a slow maxillary expansion type with some modification. In $\mathrm{P}$ group, after The $8^{\text {th }}$ day based on previous research were placed into Hype animal chamber for HBOT with 2,4 ATA pure oxygen (100\%) for 90 minutes (3 $X 30$ minutes) with interval 5 minutes of breathing normal air (normobaric) until the $14^{\text {th }}$ day.

After given treatments according to the assessed groups for 14 days, the pressure of oxygen was decreased until 1 ATA, Guinea pigs were euthanized in lethal dose with combination ketamine and acepromazine $1: 1$ in dose $(0.05$ $\mathrm{mg} / \mathrm{kg}$ bw), and the maxilla was decapitated. Specimens of the maxilla were cut transversely and placed in $10 \%$ buffer formaline before made into slides and then coloured using Hematoxyllin eosin colouration. Histological slide of blood vessels number, osteoblast, and new bone formation were examined under light microscope Olympus type CX 31 in 40X magnification. The calculation of osteoblast and blood vessels number is performed at three field of each slides. New bone formation measurement is a result from bone surface area reduced by cartilaginous in maxillary suture.

Data obtained from the calculation number of in tension area were tabulated and were analyzed by regression test to know the correlation between blood vessels number, osteoblast, and new bone formation by giving when maxillary suture was expanded.

\section{RESULTS}

\section{Clinical evaluation}

Guinea pigs with new bone formation was followed with tooth movement. During the experiments, There was no animal death related to maxillary suture expansion or HBOT procedures.

\section{Light microscopy observation}

After 14 days, in groups which did not receive HBOT, cartilage matrix formation was dominant both in control (Figure 1). New bone formation was observed to start from the cartilaginous margins and extended through the center in $\mathrm{P}$ groups that giving HBOT 2,4 ATA given from day 8-14 as result of research groups are as shown in the picture below:

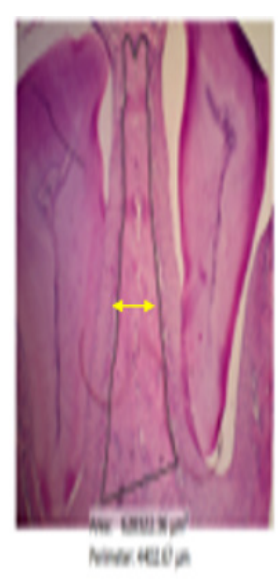

A

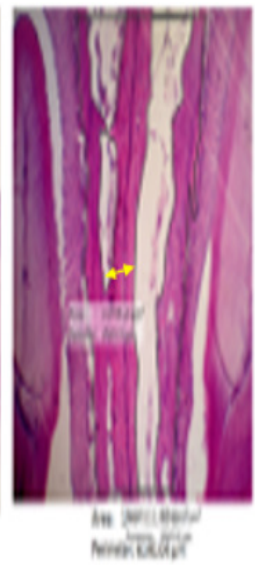

B

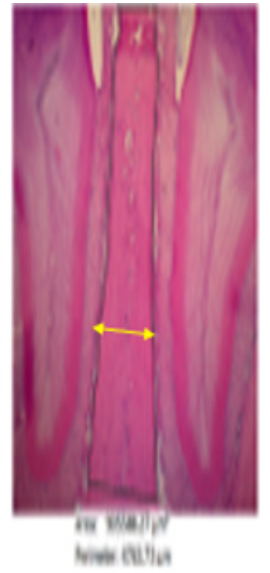

C
Figure 1. Hematoxyllin Eosin colouration of new bone formation with 40x magnification of during maxillary suture expansion. Notes: A. K(-) group; B. K(+) group; C. P group

Results from research were analysed descriptively to obtain distribution and summary of data hence clarifying results presentation, and then is regression tests were done using analytic statistic tests with significant level of $95 \%(p=0,05)$ using SPSS version 17 programme.

Research data in table 1 shows a linear increase from $\mathrm{K}(-)$ to P. Table shows that the HBOT increased Blood vessels number in tension area during maxillary suture expansion. 
Table 1. Data results of the means and standard deviations blood vessels number given by HBOT

\begin{tabular}{ccc}
\hline Group & Mean (cells) & Standard Deviation \\
\hline $\mathrm{K}(-)$ & 2.44 & \pm 0.34 \\
$\mathrm{~K}(+)$ & 3.61 & \pm 0.57 \\
$\mathrm{P}$ & 9.33 & \pm 0.52 \\
\hline
\end{tabular}

Table 2. Data results of the means and standard deviations osteoblast number number given by HBOT

\begin{tabular}{ccc}
\hline Group & Mean (cells) & Standard Deviation \\
\hline $\mathrm{K}(-)$ & 14.87 & \pm 0.61 \\
$\mathrm{~K}(+)$ & 20.23 & \pm 0.91 \\
$\mathrm{P}$ & 37.95 & \pm 1.85 \\
\hline
\end{tabular}

Table 3. Data results of the means and standard deviations new bone formation given by HBOT completed with data result of bone surface area and cartilaginous areas

\begin{tabular}{ccccccc}
\hline Group & $\begin{array}{c}\text { Mean } \\
\text { of bone } \\
\text { surface } \\
\text { area }\end{array}$ & SD & $\begin{array}{c}\text { Mean of } \\
\text { cartilage } \\
\text { nous } \\
\text { area }\end{array}$ & SD & $\begin{array}{c}\text { Mean } \\
\left(\mathrm{mm}^{2}\right)\end{array}$ & SD \\
\hline $\mathrm{K}(-)$ & 0.66 & \pm 0.18 & 0.35 & \pm 0.08 & 0.30 & \pm 0.16 \\
$\mathrm{~K}(+)$ & 0.84 & \pm 0.32 & 0.52 & \pm 0.33 & 0.32 & \pm 0.1 \\
$\mathrm{P}$ & 1.14 & \pm 0.24 & 0.43 & \pm 0.19 & 0.68 & \pm 0.32 \\
\hline
\end{tabular}

Figure 2. Bar diagram of influence HBOT to blood vessels, osteoblast number, and new bone formation in tension area during maxillary suture expansion

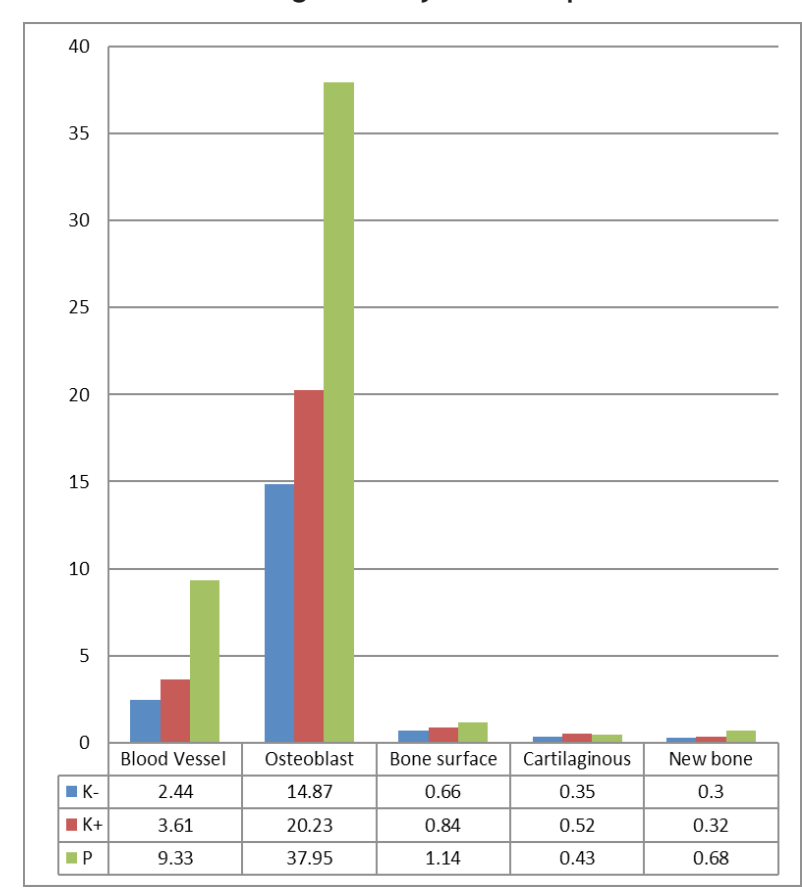

Before conducting hypothesis test, a normality test for each group was conducted using Shapiro-Wilk test, as the samples were less than 50. Results from Shapiro-Wilk test showed that the data were distributed normally.
Table 4. Linear regression test of HBOT treatment group

\begin{tabular}{cc}
\hline Group & Significance (R) \\
\hline $\mathrm{K}(-), \mathrm{K}(+), \mathrm{P}$ & .695 \\
\hline & \\
Table 5. ANOVA test of HBOT treatment group \\
\hline Group & Significance (P) \\
\hline $\mathrm{K}(-), \mathrm{K}(+), \mathrm{P}$ & .007 \\
\hline
\end{tabular}

With linear regression test showed that there is strong positive correlation between blood vessels number and osteoblast number to new bone formation with coefficient of multiple determination $\mathrm{R}=6.95$ in HBOT during maxillary suture expansion. Greater blood vessels number and new bone formation is associated, so is the osteoblast number and new bone formation, with $p$ values has significancy 0.01 (less than significance level $(p \leq 0.05)$. Anova test results signified that all groups in this research had a significant difference 0.007 ( $p \leq 0.05)$ between blood vessels number, osteoblast number and new bone formation with HBOT during maxillary suture expansion.

\section{DISCUSSION}

Results from descriptive statistic tests showed that the highest means of blood vessels number, osteoblast number, and new bone formation is $P$ group that given with HBOT in 2,4 ATA. This was due to the fact that HBOT could increase neovascularization and angiogenesis that is closely related in bone formation process-in increasing osteoblastic activity. ${ }^{12}$ Osteoblast plays a role in the synthesis of bone components, specifically the type I-collagen, proteoglycan and glycoprotein which includes osteonectin. ${ }^{11}$

Figure 2 show when $\mathrm{K}(+)$ treated by maxillary expansion there is minimal new bone formed compare to $\mathrm{K}(-)$ is a normal. Based on our research, we speculate that helical spring that we used here as slow maxillary expansion would have a less forced to make skeletal effect. ${ }^{13}$ Helical spring approaches were able to make some changes, especially at dental level also transversal level changes involved both skeletal and dentoalveolar due to maxillary expansion. ${ }^{14}$

The midpalatal suture has been desc 'ribed as an end-to-end type of suture with characteristic changes in its morphology during growth. ${ }^{15,16,17}$ In the infantile period, Melsen reported that the 
midpalatal suture is broad and Y-shaped in its frontal sections. ${ }^{18}$

The ossification process in the midpalatal suture starts with bone spicules from suture margins along with bone islands (bone masses of acellular tissue and inconsistently calcified tissue) in the middle of the sutural gap as we see in image 1 in $\mathrm{K}(+) .{ }^{16,13}$

The formation of spicules during sutura maxillary expansion occurs in many places along the suture, with the number of spicules increasing with maturation ${ }^{13}$ and forming many scalloped areas that are close to each other and separated in some areas by connective tissue..$^{15}$ Concomitantly, interdigitation increases; then fusion occurs earlier in the posterior area of the suture, with progression of ossification taking place from posterior to anterior, with resorption of cortical bone in the sutural ends and formation of cancellous bone. ${ }^{15,18,19}$

Remodeling of the bone margins of the palatal suture was evident with different maturation stages of the newly-formed bone areas characterized by wide osteocyte lacunae. ${ }^{14}$ Seven days after the end of expansion newly-formed bone with osteoid matrix undergoing mineralization was evident on the bone margins and from within the center of the suture, as was the peculiar fishbone appearance of the trabecular bone. ${ }^{4}$ Moreover, newly-formed bone showed collagen fibers in a transversal orientation related to the suture long axis where a longitudinal orientation was observed This orientation was suggested to be related to the response to mechanical forces. ${ }^{20}$ Once the midpalatal suture separation is obtained, the amount of expansion might affect the healing time of the bone that starts after the midpalatal separation and keeps going for several months after. ${ }^{14}$

$P$ group was helical spring that given with HBOT showed that increasing blood vessel number and new bone formed than $\mathrm{K}(+)$ group as seen as table 1 and figure 2 . It is indicated that HBOT during maxillary suture expansion can accelerated new bone formation. It is marked with spongiosa bone replaced with compact bone.

Regression test showed that there is strong positive correlation between blood vessels number and osteoblast number to new bone formation with coefficient of multiple determination $\mathrm{R}=6.95$ in HBOT during maxillary suture expansion as indicated in table 4. Greater blood vessels number and new bone formation is associated, so is the osteoblast number and new bone formation have synergistic effect. Bone is a highly vascularized connective tissue. Skeletal vasculature plays a significant role in the process of bone remodelling to maintain skeletal integrity. ${ }^{21}$ Successful bone regeneration and remodeling largely depends on a proper blood supply. ${ }^{22}$ Both physical and biochemical, between blood vessels and bone cells are connected while many factors involved in the conversation between endothelial cells (EC) and osteoblasts $(\mathrm{OB})$ during both bone formation and repair such as BMP-2, OP-1. ${ }^{23}$

Sutura maxillary expansion will cause deformation of the blood vessels and the irregularity of tissues around the tooth. As a result, there will be change in cell metabolism due to the hypoxic condition and decreased nutrition levels ${ }^{20}$ This would cause the local inflammation process. HBOT has mechanism to decrease inflammation. ${ }^{24}$

During inflammation under hypoxia an increase of VEGF mRNA could be shown, and in addition to that the RNA's half-life was extended. This effect is translated by the hypoxia sensitive transcription factor HIF-1. ${ }^{11}$ HBOT could increase the levels of vascular endothelial growth factor (VEGF) and basic fibroblast growth factor (bFGF) are the most extensively angiogenic factors which causes neovascularization and angiogenesis that is closely related in increasing osteoblastic activity and vital for new bone formation process. ${ }^{12}$ VEGF acts as mitogen especially on endothelial cells, raises the vessel permeability and dilatation by releasing $N O$ and has chemotactic impact on other growth promoting cell populations ${ }^{25}$ Decrease of proinflammation mediators which causes the hampered formation and activity of osteoblast proliferates dan differentiates into mature osteoblasts hence the number of osteoblast increases bone remodeling new bone formation and the bone density would increase as well. ${ }^{5}$ VEGF $_{164}$ activates the PI3K/AKT pathway in osteoblasts and induces a stabilization and signal transduction by the main component of the Wnt signaling pathway, B-catenin. Overexpression of VEGF $_{164}$ isoform leads to osteosclerosis, highly increased bone formation, accompanied by an intensified osteoblast differentiation resulting in 
bone overgrowth and altered bone morphology 25 This indicates a need for a tight angiogenesis control during bone development. ${ }^{26}$

Hyperbaric oxygen therapy (HBOT) improves angiogenesis. Previous research showed that HBOT resulted in a significantly increased new bone formation and angiogenesis compared to the sole treatment with autologous bone grafting that proved that HBOT have role in both angiogenesis and bone regeneration. ${ }^{27}$ Over about 30 treatments new vessel growth infiltrated the wound and achieved $\mathrm{pO}_{2}$ 's of about $85 \%$ of control tissue. ${ }^{28}$ Capillary venous oxygen saturation $\left(\mathrm{SO}_{2}\right)$ showed a significant increase in the HBOT.27 The mechanism of action of HBOT in increasing neovascularization is probably not directly related to angiogenesis. ${ }^{28}$ The production of growth factors such as VEGF was not enhanced and no effect of HBOT on vasodilatory capability in ulcer tissue was observed. The mechanisms of HBOT action have been proposed ${ }^{27}$ : (1). HBOT transports oxygen to bodily sites where vascularization is poor or absent, such as in poorly healing wounds. This proposed mechanism of HBOT action relates to the physical relationship between pressure and gas concentration in a liquid It is known that 2.4 ATA of pure oxygen dissolves a substantial amount of oxygen in blood plasma; (2). Cyclic periods of hyperbaric oxygen and normoxic oxygen create a stress response by repeatedly increasing and decreasing the number of reactive oxygen species (ROS) in the tissues. ROS influence the signal transduction pathways of multiple growth factors, including those implicated in propagating angiogenesis. ${ }^{28}$

HBOT itself affect to stimulate the proliferation and differentiation of human osteoblasts in vitro. On the other hand, HBO enhanced biomineralization with an increase in bone nodule formation, calcium deposition, and alkaline phosphatase activity (29) and also expression of collagen type 1 and Runx-2. ${ }^{(10)}$ HBOT significantly promoted osteoblast proliferation and cell cycle progression after 3 days of treatment. (27) HBOT stimulated significantly increased mRNA expression of fibroblast growth factor (FGF)-2 as well as protein expression levels of Akt, p70 ${ }^{\mathrm{s}} \mathrm{k}$, phosphorylated ERK, nuclear factor (NF)-KB, protein kinase $\mathrm{C}(\mathrm{PKC}) \mathrm{a}$, and phosphorylated C-Jun $\mathrm{N}$-terminal kinase (JNK). ${ }^{(30)}$
ANOVA test results signified that all groups in this research had significance difference between blood vessels number, osteoblast number and new bone formation with HBOT during maxillary suture expansion. Osteoprogenitor cells would differentiate into osteoblast and produce osteoids. This osteoid tissues will form a vascularised bone network in an instant. After a few months, this bone network will change into trabecular bone. ${ }^{(12)}$

\section{CONCLUSION}

The general conclusion of the research is that there is intercausal relationship between increasing blood vessels number, increasing osteoblast by giving 2,4 ATA HBOT to new bone formation during maxillary suture expansion.

Specifically, the result of the research can be concluded that the use of HBOT in 2,4 ATA given from day 8-14 could increase the blood vessels number, increasing osteoblasts number and new bone formation

\section{REFERENCES}

1. Nishio C, Huynh N. Skeletal malocclusion and genetic expression: An evidence based review. J dent Sleep med 2016;3(2):57-63. DOI: $10.15331 / \mathrm{jdsm} .5720$

2. Agarwal A, Mathur R. Maxillary expansion. Int J Clin Pediatr Dent. 2010;3:139-46. DOI: 10.5005/jp-journals-10005-1069.

3. Eldin NFS, Elkordy SA, Fayed MS, Elbeialy A, Eid FH. Transverse skeletal effects of rapid maxillary expansion in pre and post pubertal subjects: A systematic review. Open Access Maced J Med Sci. 2019;2(8):1-11. DOI: 10.3889/oamjms.2019.080

4. Caprioglio A, Fastuca R, Zecca PA, Beretta M, Mangano C, Piattelli A, et al. Cellular midpalatal suture changes after rapid maxillary expansion in growing subjects: A case report. Int J Mol Sci. 2017;18(3):615. DOI: $10.3390 /$ ijms 18030615

5. Lafage-Proust $\mathrm{M}-\mathrm{H}$, Roche $B$, Langer $M$, Cleret D, Vanden Bossche A, Olivier T, et al. Assessment of bone vascularization and its role in bone remodeling. Bonekey Rep. 2015;4: 662. DOI: 10.1038\%2Fbonekey.2015.29

6. Huda N. Pengaruh hiperbarik oksigen (hbo) 
terhadap perfusi perifer luka gangren pada penderita dm di RSAL dr. Ramelan Surabaya. Thesis. Jakarta: Universitas Indonesia; 2010: 3.

7. Gokce S, Osman Bengi A, Akin E, Karacay S, Sagdic D, Kurkcu M et al. Effects of hyperbaric oxygen during experimental tooth movement. Angle Orthod. 2008;78(2):304-8. DOI: 10.2319/022507-96.1

8. Inokuchi T, Kawamoto T, Aoki K, Aoki A, Nagahama K, Baba Y. The effects of hyperbaric oxygen on tooth movement into the regenerated area after distraction osteogenesis. Cleft Palate-Craniofacial J. 2010;47(4):382-92. DOI: 10.1597\%2F09-016.1

9. ThomSR. Hyperbaricoxygen:Itsmechanismsand efficacy. Plast Reconstr Surg. 2011;127(1):13141. DOI: 10.1097\%2FPRS.0b013e3181fbe2bf

10. Al Hadi H, Smerdon GR, Fox SW. Hyperbaric oxygen therapy accelerates osteoblast differentiation and promotes bone formation. J Dent. 2015;43(3):382-8. DOI: 10.1016/j. jdent.2014.10.006. Epub 2014 Oct 23

11. Brahmanta A, Sutjipto, Narmada IB. Histological changes during orthodontic tooth movement due to hyperbaric oxygen therapy. 2016;49(2):63-66. DOI: 10.20473/j.djmkg. v49.i2.p63-66

12. Sutomo S, Rahardjo P, Sjafei A. The effect of hyperbaric oxygen in increasing the amount of osteoblast cells on remodeling process during tooth movement on male adult Cavia cobaya. Orthod Dent J. 2012;3(1):1-3.

13. Angelieri F, Cevidanes LHS, Franchi L, Gonçalves JR, Benavides E, Mc Namara JA. Midpalatal suture maturation: Classification method for individual assessment before rapid maxillary expansion. Am J Orthod Dentofac Orthop. 2013;144(5):759-69. DOI: 10.1016\%2Fj.ajodo.2013.04.022

14. Pereira JDS, Jacob HB, Locks A, Brunetto $M$, Ribeiro GLU. Evaluation of the rapid and slow maxillary expansion using conebeam computed tomography: A randomized clinical trial. Dent Press J Orthod MarApr 2017;22(2):61-68. DOI: 10.1590/21776709.22.2.061-068.0ar

15. Valdivia LMJ, Carrillo VM, Cardenas YAR, Da Silveira HLD, Guillén LEA. Midpalatal suture maturation stage assessment in adolescents and young adults using cone-beam computed tomography. Prog Orthod 2019;20(38) DOI: 10.1186/s40510-019-0291-z

16. Kwaka KH, Kima SS, Kima YI, Kima YD. Quantitative evaluation of midpalatal suture maturation via fractal analysis. Korean J Orthod 2016;46(5):323-0 DOI: $10.4041 /$ kjod.2016.46.5.323

17. Hahn W, Fricke-Zech S, Fialka-Fricke J, Dullin C, Zapf A, Gruber R et al. Imaging of the midpalatal suture in a porcine model: Flatpanel volume computed tomography compared with multislice computed tomography. Oral Surgery, Oral Med Oral Pathol Oral Radiol Endodontology. 2009;108(3):443-9. DOI: 10.1016/j.tripleo.2009.02.034. Epub 2009 May 22

18. Bright JA. The Importance of Craniofacial Sutures in Biomechanical Finite Element Models of the Domestic Pig. Plos One. 2012; 21(2) DOI: 10.1371/journal.pone.0031769

19. Fernanda Angelieri F, Franchi L, Cevidanes LHS, Silva BB, McNamara JA. Prediction of rapid maxillary expansion by assessing the maturation of the midpalatal suture on cone beam CT. Dental Press J Orthod. 2016;21(6):115-125. DOI: 10.1590/21776709.21.6.115-125.sar

20. Li M, Zhang Z, Gu X, Ye Jin Y, Feng C, Yang $S$ et al. MicroRNA-21 affects mechanical forceinduced midpalatal suture remodeling. Cell Proliferation in Basic and Clinical Science. 2019;00:e1297. DOI: $10.1111 / \mathrm{cpr} .12697$

21. Kanczler JM, Oreco RO. Bone. Osteogenesis and Angiogenesis: the Potential for Engineering Bone. Eur Cells Mater. 2008;(15):100-14. DOI: 10.22203/eCM

22. Filipowska J, Tomaszewski KA, Niedzwiedzki $\iota$, Walocha JA, Niedzwiedzki T. The role of vasculature in bone development, regeneration and proper systemic functioning. Angiogenesis. 2017;20(3):291-302. DOI: 10.1007/s10456-017-9541-1. Epub 2017 Feb $\underline{13}$

23. Saran U, Gemini Piperni S, Chatterjee S. Role of angiogenesis in bone repair. Arch Biochem Biophys. 2014;1(561):109-17. DOI: 10.1016/j. abb.2014.07.006. Epub 2014 Jul 14.

24. Zainal ASH, Yamamoto Z, Zainol Abidin LZ, Megat Abdul Wahab R, Zainal AZ. Cellular 
and molecular changes in orthodontic tooth movement. Scientific World J. 2011;11:1788803. DOI: $10.1100 \% 2 F 2011 \% 2 F 761768$

25. Jung S, Wermker K, Poetschik H, Ziebura T, Kleinheinz J. The impact of hyperbaric oxygen therapy on serological values of vascular endothelial growth factor (VEGF) and basic fibroblast growth factor (bFGF). Head Face Med. 2010;6(1):29. DOI: 10.1186\%2F1746160X-6-29

26. Patil AS, Sable RB, Kothari RM. Occurrence, biochemical profile of vascular endothelial growth factor (VEGF) isoforms and their functions in endochondral ossification. Journal of Cellular Physiology. 2012;227(4):1298-308. DOI: $10.1002 / j c p .22846$

27. Thelen S, Sager M, Wild M, Grassmann JP, Schneppendahl J, Hakimi AR, et al. Hyperbaric Oxygen Therapy Improves Angiogenesis and Bone Formation in Critical Sized Diaphyseal
Defects. J Orthop Res. 2015;33(4):513-20. DOI: $10.1002 /$ jor. 22805

28. Van Neck JW, Tuk B, Fijneman EMG, Redeker JJ, Talahatu EM, Tong M. Hyperbaric oxygen therapy for wound healing in diabetic rats: Varying efficacy after a clinically-based protocol. PLoS One. 2017;12(5). DOI: 10.1371/ journal.pone.0177766.eCollection 2017.

29. Li J, Liu CY, Jiang YF, Wei XZ, Li JU. Proliferation and differentiation of human osteoblasts from a type 2 diabetic patient in vitro. Genet $\mathrm{Mol}$ Res. 2015;14(3):11292-9. DOI: 10.4238/2015. September.22.23

30. Hsieh CP, Chiou YL, Lin CY. Hyperbaric oxygen-stimulated proliferation and growth of osteoblasts may be mediated through the FGF-2MEKERK 12NF-KB and PKCJNK pathways. Connect Tissue Res. 2010;51(6):497-509. DOI: 10.3109/03008201003746679. Epub 2010 May 24. 